\title{
S2k guideline on diagnosis and treatment of atopic dermatitis - short version
}

Thomas Werfel' ${ }^{1}$, Annice Heratizadeh'1 Werner Aberer², Frank Ahrens ${ }^{3}$, Matthias Augustin ${ }^{4}$, TIllo Biedermann 5 , Thomas Diepgen ${ }^{6}$, Regina Fölster-Holst? ${ }^{7}$, Uwe Gieler ${ }^{8}$, Julia Kahle ${ }^{9}$, Alexander Kapp', Alexander Nast ${ }^{10}$, Katja Nemat ${ }^{11}$, Hagen OtT'12, Bernhard Przybilla ${ }^{13}$, Martin Roecken ${ }^{14}$, Martin Schlaeger ${ }^{15}$, Peter Schmid-Grendelmeier ${ }^{16}$, Jochen Schmitt ${ }^{17}$, Thomas Schwennesen 18 , Doris StaAB 19 , MarGitta Worm 20

'Abteilung für Immundermatologie und experimentelle Allergologie, Klinik für Dermatologie, Allergologie und Venerologie, Medizinische Hochschule Hannover, Deutschland; '2Universitätsklinik für Dermatologie und Venerologie, Medizinische Universität Graz, Österreich; ${ }^{3}$ Abteilung für Pädiatrie, Altonaer Kinderkrankenhaus, Hamburg, Deutschland; ${ }^{4}$ Kompetenzzentrum Versorgungsforschung in der Dermatologie (CVderm), Institut für Versorgungsforschung in der Dermatologie und bei Pflegeberufen (IVDP), Universitätsklinikum Eppendorf, Hamburg, Deutschland; ${ }^{5}$ Klinik und Poliklinik für Dermatologie und Allergologie am Biederstein, Technische Universität München, Deutschland; ${ }^{6} I n s t i t u t$ für Klinische Sozialmedizin, Hautklinik, Universitätsklinikum Heidelberg, Deutschland; ${ }^{7}$ Klinik für Dermatologie, Venerologie und Allergologie, Universitätsklinikum Schleswig-Holstein, Campus Kiel, Deutschland; ${ }^{8}$ Klinik für Dermatologie, Venerologie und Allergologie, Justus-Liebig-Universität Gießen, Deutschland; ${ }^{9}$ Deutscher Allergie- und Asthmabund (DAAB) e. V., Mönchengladbach, Deutschland; ${ }^{10}$ Klinik für Dermatologie, Venerologie und Allergologie, Charité - Universitätsmedizin Berlin, Deutschland; "1Praxis für Kinderpneumologie und Allergologie, Kinderzentrum DresdenFriedrichstadt (Kid), Dresden, Deutschland; ${ }^{2}$ Fachbereich Pädiatrische Dermatologie und Allergologie, Kinder- und Jugendkrankenhaus Auf der Bult, Hannover, Deutschland; ${ }^{13}$ Klinik und Poliklinik für Dermatologie und Allergologie, Ludwig-Maximilians-Universität München, Deutschland; ${ }^{14}$ Universitäts-Hautklink Tübingen, Eberhard-Karls-Universität Tübingen, Deutschland; ${ }^{15}$ Praxis für Dermatologie, Oldenburg, Deutschland; ${ }^{16}$ Allergiestation, Dermatologische Klinik,

Development stage $\mathrm{S} 2 \mathrm{k}$

ICD-10-Number L20.8, L20.9, L28.0

AWMF register number 013-027

Date of production April 2008

Last revision

March 2015

Valid until

May 2018

Next revision May 2018

German version www.springermedizin.de/ allergo-journal UniversitätsSpital Zürich, Schweiz; ${ }^{17 Z e n t r u m ~ f u ̈ r ~ E v i d e n z b a s i e r t e ~ G e s u n d h e i t s f o r s c h u n g, ~ T e c h n i s c h e ~ U n i v e r s i t a ̈ t ~}$ Dresden, Deutschland; ${ }^{18}$ Deutscher Neurodermitisbund (DNB) e. V., Hamburg, Deutschland; ${ }^{19} \mathrm{Klinik}$ für Pädiatrie m. S. Pneumologie und Immunologie, Charité Campus Virchow-Klinikum, Berlin, Deutschland; ${ }^{20}$ Allergie-Centrum-Charité, Klinik für Dermatologie, Venerologie und Allergologie, Charité - Universitätsmedizin, Berlin, Deutschland

\section{Summary}

Atopic dermatitis (AD) represents a pruritic, non-contagious, chronic or chronically relapsing, inflammatory skin disease. The course of the disease may be complicated by bacterial or viral superinfections. The first manifestation of the disease and further flare-ups are due to genetic predisposition and also to a variety of further trigger factors. The therapy regimen should be adapted to disease symptoms that are actually present and consider individual features of the disease as reported by the patients or their parents.

This short version of the German guideline on $\mathrm{AD}$ provides an overview of evidence-based diagnostic and treatment options. All recommendations made

This guideline was originally published in Journal of the German Society of Dermatology. J Dtsch Dermatol Ges 2016;14(1):92-105. DOI: $10.1111 / d d g .12871$. here are the result of a consensus of the scientific medical societies, working groups and support groups based on scientific data published to date. Abstracts and details of the studies cited are provided in the long version of this guideline (see: www. awmf.org).

Cite this as Werfel T, Heratizadeh A, Aberer W, Ahrens F, Augustin M, Biedermann T, Diepgen T, Fölster-Holst R, Gieler U, Kahle J, Kapp A, Nast A, Nemat K, Ott H, Przybilla B, Roecken M, Schlaeger M, Schmid-Grendelmeier P, Schmitt J, Schwennesen T, Staab D, Worm M. S2k guideline on diagnosis and treatment of atopic dermatitis - short version. Allergo J Int 2016;25:82-95

DOI: 10.1007/s40629-016-0104-6 


\section{Introduction}

\subsection{Nomenclature}

The committee that produced this guideline agreed to use the term ,atopic dermatitis“ in this guideline, which can be used as a synonym for "atopic eczema“ and is also the current term used by patients.

\subsection{Methodology}

This is the short version of the S2k guideline on atopic dermatitis, which was published in a long version under register number 013-027 on the AWMF website (www.awmf.org), listing original studies that led to the recommendations. This guideline is an update of the AWMF S2 atopic dermatitis guideline published in 2008/2009, in which the methodology is presented in more detail $[1,2]$.

The 2008 guideline was an S2e guideline, for which meta-analyses, clinical studies and other scientific investigations were collated through a systematic literature search in PUBMED and provided as a handout to the participants in the consensus conference. For the update, the literature search was conducted up to January 2014. In addition, individual studies were supplemented.

\begin{tabular}{|c|c|}
\hline \multicolumn{2}{|c|}{ Abbreviations } \\
\hline AGNES & $\begin{array}{l}\text { Atopic dermatitis education working } \\
\text { group, Arbeitsgemeinschaft Neuro- } \\
\text { dermitisschulung }\end{array}$ \\
\hline AWMF & $\begin{array}{l}\text { Association of the Scientific Medical } \\
\text { Societies Germany, Arbeitsgemeinschaft } \\
\text { der Wissenschaftlichen Medizinischen } \\
\text { Fachgesellschaften }\end{array}$ \\
\hline BMG & $\begin{array}{l}\text { Federal Ministry of Health, Bundesminis- } \\
\text { terium für Gesundheit }\end{array}$ \\
\hline DDG & $\begin{array}{l}\text { German Dermatological Society, } \\
\text { Deutsche Dermatologische Gesellschaft }\end{array}$ \\
\hline EASI & Eczema Area and Severity Index \\
\hline ECP & Eosinophilic cationic protein \\
\hline GKV & $\begin{array}{l}\text { Statutory health insurance, Gesetzliche } \\
\text { Krankenversicherung }\end{array}$ \\
\hline IGA & Investigator's Global Assessment \\
\hline KASK & $\begin{array}{l}\text { Drug safety in childhood committee, } \\
\text { Kommission für Arzneimittelsicherheit } \\
\text { im Kindesalter }\end{array}$ \\
\hline SCORAD & Scoring Atopic Dermatitis \\
\hline STIKO & $\begin{array}{l}\text { Vaccine standing committee, Ständige } \\
\text { Impfkommission }\end{array}$ \\
\hline TARC & $\begin{array}{l}\text { Thymus and activation regulated } \\
\text { chemokine }\end{array}$ \\
\hline TPMT & Thiopurinmethyltransferase \\
\hline
\end{tabular}

The recommendations were produced in an interdisciplinary consensus conference using a nominal group process. For those interventions for which no consensus could be achieved at the consensus conference because of time constraints, a Delphi procedure was used. The recommendation levels of the individual recommendations are expressed by standard formulations in this guideline (Tab. 1) [3].

The content of the German AWMF „Atopic dermatitis" guideline" was harmonized with the corresponding European guideline, which is also being updated at the time of publication of this guideline $[4,5]$.

\subsection{Aims of the guideline}

Atopic dermatitis is a common skin disease, both in childhood and adolescence and in adults. Because of its chronic course and characteristics of this condition, which affects many areas of life with marked impairment of quality of life, optimal medical care is desirable.

The general aim of the guideline is to make available to dermatologists, pediatricians, general physicians and other doctors involved in office and hospital treatment of atopic dermatitis an accepted decision-making tool for choosing and implementing suitable and sufficient therapy for patients with atopic dermatitis.

\subsection{Target group}

This guideline is intended for specialists in dermatology, pediatric and adolescent medicine, general medicine and all groups of physicians whose work includes the treatment of atopic dermatitis. It should also provide patients and relatives with accurate information for assessing therapeutic interventions.

\section{Atopic dermatitis - general aspects 2.1. Definition and classification}

Atopic dermatitis is a chronic or chronic relapsing, noncontagious skin disease, the classic morphology

\section{Tab. 1: Recommendation levels}

Positive

- recommended

_ can be recommended

_ can be considered

Negative

_must not be done

_ is not recommended 
and location of which differs depending on age, and which is usually associated with severe pruritus. More common complications of atopic dermatitis include infections such as disseminated impetiginization by Staphylococcus aureus, viral infections or fungal infections [6].

\section{Recommendation}

- The diagnosis and treatment of atopic dermatitis and its complications must be performed by medically qualified persons.

\subsection{Epidemiology}

The cumulative incidence of atopic dermatitis varies between 11 and $21 \%$ in Northern Europe depending on age and region. Point prevalence of $10-15 \%$ has been described in Germany. According to epidemiologic analyses from Germany, about $23 \%$ of babies and toddlers, $8 \%$ of schoolchildren and 2 to $4 \%$ of adults claim healthcare services because of atopic dermatitis. In children, atopic dermatitis is therefore the most common chronic disease overall $[7,8]$

\subsection{Pathogenesis and genetics}

The causes of atopic dermatitis are varied. Both a genetic predisposition and numerous trigger factors play an important part in the first manifestation and in exacerbations of the disease.

\subsubsection{Prevention}

Based on understanding of the pathogenesis and genetics, general measures for primary prevention of atopic dermatitis are recommended. Please refer to the current S3 guideline, „Allergy prevention“ [9].

\subsubsection{Atopic dermatitis and vaccinations}

The vaccine standing committee (STIKO) issues recommendations for effective vaccinations in Germany. Information can be obtained via the Robert Koch Institute (RKI) homepage [10]. They are also published in the „Epidemiological Bulletin“.

\section{Recommendation}

_ It is recommended that children, adolescents and adults with atopic dermatitis are vaccinated regularly according to STIKO recommendations. In an acute exacerbation, postponement of the vaccination until the skin condition has stabilized is recommended.

\subsection{Manifestations}

The skin manifestations of atopic dermatitis differ according to stage (acute or chronic) and age [6]. When the manifestations or course of inflammatory skin diseases is untypical, differential diagnoses (see 2.7.3) must be investigated, including in childhood.

\section{Recommendation \\ _ The different clinical manifestations of atopic dermatitis with its age-specific features and the most important differential diagnoses must be familiar to the treating physician.}

\subsection{Course}

The course of atopic dermatitis is variable with disease exacerbations of varying duration and severity. The disease can recur often. Even slight manifestations can sometimes result in severe restriction and psychological stress. Spontaneous cure is possible at any time. However, at least $30 \%$ of all children who suffer from atopic dermatitis suffer from eczema in adulthood, at least at times.

\section{Recommendation \\ _ Informing patients of the chronic and/or recurrent course is recommended.}

\subsection{Complications}

Infections are frequent complications of atopic dermatitis. These include:

_ Secondary infections with bacteria,

- Viral infections,

_ Fungal infections.

Complications in rare cases are eye diseases (glaucoma, keratoconus, retinal detachment, blindness), alopecia areata and growth delay or small stature (due, among other things, to hypoproteinemia as a result of exudation of inflammatory secretion or poor diet or malnutrition). Atopic dermatitis can be associated with concomitant ichthyosis vulgaris.

\section{Recommendations}

- The complications of atopic dermatitis such as viral (e.g., eczema herpeticum) and bacterial (e.g., staphylococcal) superinfections must be familiar to treating clinicians.

_ It is recommended to inform (educate) affected patients and their relatives about possible complications of atopic dermatitis. 


\subsection{Diagnosis}

\subsubsection{General remarks}

General diagnosis requires a medical history (including personal and family atopic history) and examination of the entire skin, including exact documentation. A biopsy for dermatohistopathology examination is indicated in individual cases for differential diagnosis. However, other eczema conditions cannot be distinguished with certainty histologically.

\section{Recommendations}

_ As part of general diagnosis, obtaining the medical history (including personal, family and occupational atopic history) is recommended.

_ It is recommended to examine the entire skin organ.

- It is recommended to discover possible psychosomatic, dietary or other environmental trigger factors.

- A biopsy for dermatohistopathology examination can be considered for differential diagnosis.

- The use of validated criteria for making the diagnosis is recommended when conducting clinical studies.

\subsubsection{Comorbidities}

The classic comorbidities of atopic dermatitis are the other atopic diseases such as bronchial asthma and allergic rhinoconjunctivitis. Food allergies can be a trigger factor for atopic dermatitis but the patients also often exhibit immediate allergic reactions, from contact urticaria to anaphylaxis. In addition, psychosomatic comorbidities should be noted. There is an association between atopic dermatitis and mental illness in adulthood.

\section{Recommendation}

_ It is recommended to note not only diagnosis and treatment of the skin but also the typical comorbidities of atopic dermatitis (food allergy, asthma, allergic rhinitis).

\subsubsection{Differential diagnosis}

The most important differential diagnoses are other eczema diseases (allergic contact eczema, irritant and toxic contact eczema, microbial eczema) and, in adulthood, the eczema stage of cutaneous $\mathrm{T}$ cell lymphoma.

Particularly in infancy, seborrheic eczema must be distinguished from atopic dermatitis in the differential diagnosis when this is suggested by the his- tory. Rarer differential diagnoses include scabies, psoriasis and syndromes and immune deficiency syndromes that can be associated with eczematous skin changes [11].

\section{Recommendations \\ _ When the manifestations of inflammatory skin disorders are untypical, differential diagnoses must be investigated, including in childhood. \\ _ It is recommended to distinguish atopic eczema involving the hands and feet from other eczema diseases (irritant toxic eczema, contact allergic eczema), psoriasis palmoplantaris and tinea of the hands and feet.}

\subsubsection{Objective determination of severity}

So-called „objective“ skin scores are used to document the extent and severity of atopic dermatitis lesions. Objective assessment of severity with laboratory parameters is suitable for investigation of cohorts in clinical studies but not for individual diagnosis.

\section{Recommendations \\ _ In clinical studies, recording of the objective disease severity, disease symptoms, quality of life and course is recommended $[12,13]$. Use of validated instruments is recommended for measuring these disease aspects of atopic dermatitis. The EASI (Eczema Area and Severity Index) and objective SCORAD (Scoring Atopic Dermatitis) are validated instruments for measuring objective disease severity [13]. \\ _ Determination of severity using the afore- mentioned scores can also be considered on an individual basis in routine clinical practice. \\ - Measurement of laboratory parameters to determine the severity of atopic dermatitis (thymus- and activation-regulated chemokine [TARC], eosinophilic cation protein [ECP] etc.) is not recommended in routine clinical practice and can be considered in the context of clinical studies.}

\subsubsection{Allergy diagnosis}

The importance of allergic reactions in atopic dermatitis must be examined individually. IgE-mediated sensitization to environmental allergens (pollen, animal dander, house dust mites, fungi, foods etc.) can often be demonstrated. The clinical relevance of the sensitization must be determined individually by elimination and/or provocation testing. Sensitization alone does not justify any elimination or therapeutic measures. 
Skin testing with low molecular weight contact allergens can reveal additional allergic contact dermatitis in patients with refractory atopic dermatitis or a more prolonged disease course.

\section{Recommendations}

_ Individual allergy testing is recommended in atopic dermatitis depending on the findings and history.

_ Prick testing and/or measurement of specific lgE antibodies is recommended for individual allergy diagnostics according to the patient's history. The clinical relevance of the sensitization must be determined individually by means of elimination and/or provocation tests.

_ Skin tests with protein allergens (known as atopy patch test) is not recommended in routine diagnostics.

_ Skin tests with low molecular weight substances to reveal an additional contact allergy is recommended in atopic dermatitis when suggested clinically or by the history.

\subsection{Provocation factors}

The status of provocation factors is individually very varied. Knowledge of provocation factors and avoiding or reducing them is part of an individual treatment plan.

\section{Recommendation \\ _ It is recommended to identify individual provocation factors. Apart from allergens, these include, in particular, skin irritants and also psychological factors, climate influences and hormonal factors.}

\subsection{Disease costs}

Expenditure per patient for the treatment of atopic dermatitis is considerable. In combination with the high prevalence, the total burden for paying agencies is high. Affected patients and families also bear not inconsiderable additional private costs, which are difficult to determine [14]. It is worth mentioning that patients with atopic dermatitis show greater readiness to pay with the relatively quite reduced quality of life [15].

Since 2004, the reimburseability of non-prescription medicines has been excluded by the legislature as part of the modernization law on statutory health insurance (GKV). Since then, the costs for basic therapeutic agents, even when they contain urea, must be met by patients with atopic dermatitis themselves, although their regular use is recommended (see 3.1). An exception is made for children up to the age of 12 years and in those with developmental disorders up to 18 years.

\section{Recommendation}

_ Atopic dermatitis is associated with considerable direct, indirect and intangible costs. The costly basic care for patients is equivalent to basic therapy so it is recommended that the cost be borne by the statutory health insurance companies.

\subsection{Management, general aspects}

The treatment of atopic dermatitis requires a variety of measures that should be adapted individually to the patient. Treatment of the often troublesome pruritus is a particular challenge.

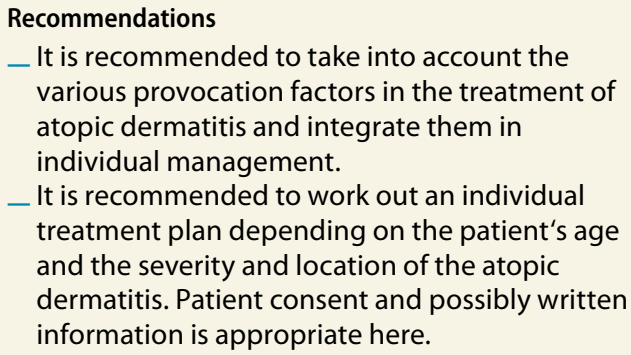

\subsection{Occupational dermatology aspects}

Special attention should be directed toward prevention strategies for patients with an atopic skin diathesis [16]. Individual recommendations regarding skin protection and skin cleaning are necessary. If a treatment contract is granted as a result of a dermatologist's report, which dermatologists or occupational physicians can produce for the accident insurer (employer's liability insurance association), treatment can be billed through the accident insurer [17].

\section{Recommendations}

_ It is recommended to investigate potential occupational trigger factors of atopic dermatitis in working patients.

_ It is recommended to reduce potential occupational trigger factors of atopic dermatitis and/or implement skin preventive measures in the area of prevention.

_ If conditions permit, production of a dermatologist's report is recommended.

- When advising adolescents, it is recommended to address occupational aspects and to consider the disease atopic dermatitis in the context of an occupational consultation by atopic dermatitis therapists. If hand eczema has already occurred in adolescence in the context of atopic dermatitis, adoption of wet occupations is not recommended. 


\subsection{Care structure}

\section{Recommendations}

_- Depending on the severity of the atopic dermatitis and/or diagnostic question (e.g., provocation test with allergens), ambulant, partly inpatient or fully inpatient treatment is recommended.

- Rehabilitation measures can be considered in chronic atopic dermatitis for patients and their legal custodians (usually parents).

- Atopic dermatitis education (for parents, children and adolescents according to the AGNES curriculum or adults) in an ambulant setting or during inpatient rehabilitation is recommended.

\subsection{Treatment principles in atopic dermatitis}

\section{Recommendations}

- Depending on the severity of the atopic dermatitis, topical treatment methods and/or systemic treatments are recommended.

- Complementary medicine methods must be evaluated after controlled studies are available, and their use can then be considered.

\subsection{Step treatment in atopic dermatitis}

\section{Recommendations}

_ It is recommended to implement step treatment appropriate to the clinical severity.

_-Depending on skin condition, four treatment steps are proposed, based on this international recommendation (Fig. 1).

\section{Evaluations of single treatment methods for drug therapy of atopic dermatitis}

\subsection{Basic therapy}

Basic therapy has special importance in the treatment of atopic dermatitis, as the disturbance of the skin barrier, genetically determined or caused by the inflammation, contributes critically to the course of the disease according to current understanding and probably can also promote new sensitizations through the skin. In the long version of the atopic dermatitis guideline, over 20 clinical studies of the efficacy of basic therapeutic agents in atopic dermatitis are mentioned or summarized.

\section{Recommendations}

- The use of basic therapeutic agents for the treatment of atopic dermatitis is recommended.

- The use of basic therapy appropriate to the skin condition (e.g., oily ointment bases on dry skin or hydrating oil-in-water emulsions for less dry skin) is recommended in atopic dermatitis even in the absence of signs of inflammation.

- Appropriate skin cleansing including baths as a component of basic therapy is recommended.

_ It is recommended to prescribe basic therapeutic agents that do not contain any frequent contact allergens.

_ Addition of urea and glycerin to the basic therapy can be recommended. However, urea is not recommended in infants. Prior testing for tolerability is recommended if skin is inflamed and in small children because of possible irritation.

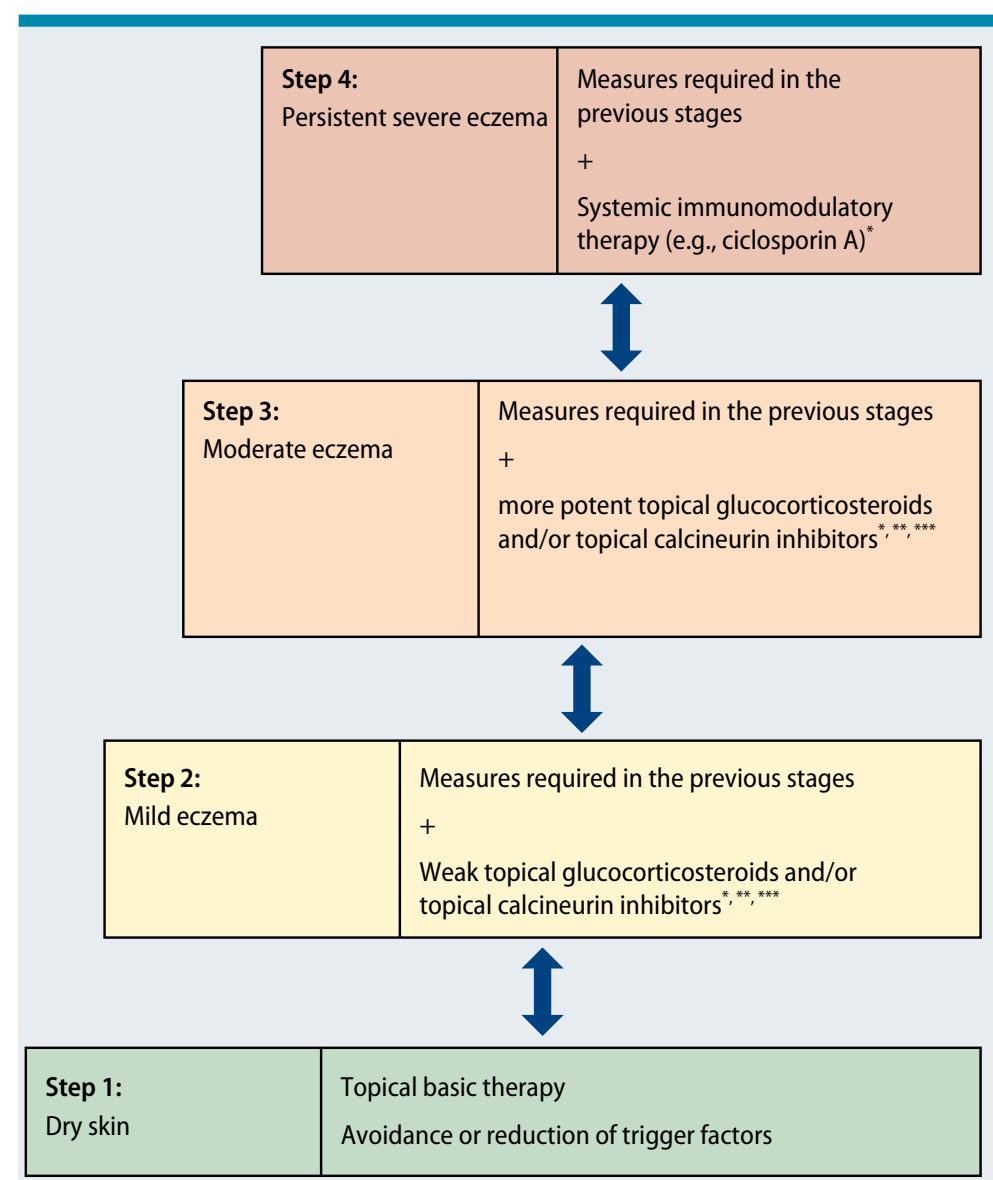

"UV therapy often is indicated from stage 2 (considering age restrictions UV therapy is not recommended during childhood). Caution: No combination with ciclosporin A and topical calcineurin inhibitors. ${ }^{* *}$ First-line therapy: Normally topical glucocorticosteroids; in case of intolerance/non-efficacy and in special body areas (face, intertriginous areas, genital area, scalp in infants) use of topical calcineurin in hibitors. ${ }^{* * *}$ Additional application of anti-pruritic and antiseptic substances can be considered. (Note: For reasons of clarity Fig. 1 does not list all treatment options discussed in this guideline.)

Fig. 1: Multi-stage treatment concept for atopic dermatitis 


\subsection{Topical therapy with glucocorticosteroids}

Topical glucocorticosteroids have been available for 50 years for the treatment of acute, subacute and chronic eczematous areas; they are divided into four classes in Europe as regards their potency (and into seven classes in the American literature). In the long version of the atopic dermatitis guideline, over 100 clinical studies of the efficacy of topical glucocorticosteroids in atopic dermatitis are mentioned or summarized, the results of which contributed to the recommendations in this guideline.

\section{Recommendations}

- The use of topical glucocorticosteroids for antiinflammatory treatment is recommended, taking into account the benefit and side effect profile.

_ Treatment with topical glucocorticosteroids is usually recommended once daily, and twice daily in exceptional cases. Furthermore, treatment until healing of the individual lesions is recommended.

_ Long-term daily treatment is not recommended.

_ Topical glucocorticosteroids must be used as regards their potency according to the local severity, location and patient's age. Escalation of the potency is recommended if the effect is insufficient.

_ Problem areas for treatment with topical glucocorticosteroids are the face, neck, intertriginous areas and scrotum, and in infants and toddlers the scalp also because of the increased absorption. The increased risk of absorption under occlusion (e.g., in the napkin area) should be considered.

_ It is recommended not to use topical glucocorticosteroids in these areas for longer than a few days.

_ Individual investigation is recommended if there is no response of the atopic dermatitis to topical glucocorticosteroids (reduced adherence, e. g. because of "fear of cortisone", unsuitable vehicle, allergy to glucocorticosteroids, continuing triggering of the atopic dermatitis by trigger factors).

- Temporally limited interval therapy with suitable topical glucocorticosteroids (e.g., fluticasone propionate, methylprednisolone aceponate) beyond the healing phase is recommended.

_ Following the acute therapy, proactive intermittent follow-up treatment for several months (usually three-monthly initially) once or twice a week on previously diseased areas can be recommended.

- Infants and toddlers in particular are more susceptible with regard to undesirable effects. More prolonged use of more potent glucocorticosteroids (class III) is usually not recommended in infants and toddlers. The longer-term use of class IV glucocorticosteroids (exception: hands, feet) is not recommended in all age groups.

\subsection{Topical calcineurin antagonists and 3.4. Discussion for oncogenic potential of calcineurin inhibitors}

Topical calcineurin antagonists have been available since 2002 for the treatment of atopic dermatitis. Like treatment with topical glucocorticosteroids, they are a symptomatic anti-inflammatory therapy, though the range of undesirable drug effects of the two drug groups is different. In the long version of the atopic dermatitis guideline, over 50 clinical studies of the efficacy of topical calcineurin antagonists in atopic dermatitis are mentioned or summarized, the results of which contributed to the recommendations in this guideline. As discussed in more detail in the long version, there is no convincing evidence, either from controlled studies with follow-up of patients or from studies of patient databases, that calcineurin in hibitors can induce malignant disease (squamous cell carcinoma, malignant lymphoma) when used topically.

\section{Recommendations}

_ Topical calcineurin inhibitors are recommended especially when topical glucocorticosteroids cannot be used or may lead to local irreversible undesirable effects over the duration of treatment.

- Because of the undesirable drug effect profile of glucocorticosteroids, calcineurin inhibitors can be recommended as first-line-therapy in „problem areas" (e.g., face, intertriginous areas, genital region, scalp in infants).

_- Observation of age restrictions is recommended (use only for children aged 2 years or older, and use of $0.1 \%$ tacrolimus only for children and adolescents aged 16 years or older). Use in infants and toddlers can be recommended in an individual case, however, especially those with severe chronic eczema of the face/cheeks. In this situation, informing the parents in detail regarding the off-label use and benefit-side effect profile is recommended.

_ Temporally limited interval therapy with topical calcineurin inhibitors beyond the healing phase is recommended.

_ Following the acute therapy, proactive intermittent follow-up treatment for several months (usually three-monthly initially) twice a week on previously diseased areas can be recommended.

_ An effective sunscreen is recommended.

_ A treatment pause is recommended if cutaneous viral infections occur in the treatment area.

- The combination of topical calcineurin inhibitors with phototherapy is not recommended. 


\subsection{Antipruritic topical agents and other anti- inflammatory topical agents \\ 3.5.1 Antipruritic agents}

Polidocanol: Polidocanol has an anesthetic and antipruritic action. There are no controlled clinical studies of formulations containing this substance. Systemic undesirable drug effects have not been described. Polidocanol leads only rarely to contact allergy.

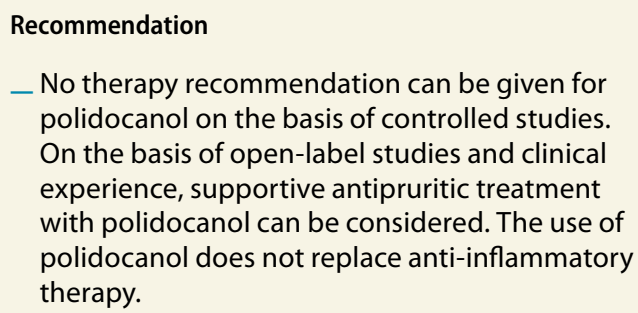
polidocanol on the basis of controlled studies. On the basis of open-label studies and clinical experience, supportive antipruritic treatment with polidocanol can be considered. The use of polidocanol does not replace anti-inflammatory therapy.

Tannins: The effect of tannins is based on an astringent action. In dermatological therapy, both synthetic (e.g., topical agents containing tamol) and natural tannins (e.g., black tea) are available. There are no controlled studies of the effects of tamol treatment in atopic dermatitis but only open-label observations of use.

\section{Recommendation}

_ No therapy recommendation can be given for tannins on the basis of controlled studies. On the basis of open-label studies and clinical experience, supportive antipruritic treatment with tannins can be considered. The use of tannins does not replace anti-inflammatory therapy.

\subsubsection{Other anti-inflammatory topical agents}

Zinc: Topical agents containing zinc have an astringent, anti-inflammatory and cooling effect. However, there are no controlled studies of efficacy in atopic dermatitis.

\section{Recommendationn \\ - No therapy recommendation can be given on the basis of controlled studies. On the basis of general clinical experience, zinc in basic therapeutic agents can be recommended.}

Shale oil (bituminosulfonates): Bituminosulfonates are a mixture containing approximately 120 different components, which have anti-inflammatory ef- fects in vitro, among other effects. In the long version, a controlled study of efficacy is summarized.

\section{Recommendation}

_ On the basis of general clinical experience, treatment with shale oils can be considered.

Products containing coal tar: Products containing coal tar have been used more and more rarely in recent years for the topical treatment atopic dermatitis. In the long version, a controlled study of efficacy is summarized.

\section{Recommendation}

- The use of products containing coal tar can be considered in exceptional cases (e.g., chronic lichenified eczema in adults).

\subsection{Antimicrobial and antiseptic substances 3.6.1. Topical and systemic antibiotics}

The skin is colonized with Staphylococcus aureus in up to $90 \%$ of cases of atopic dermatitis, components or secretion products of which are blamed for worsening skin inflammation in atopic dermatitis. Staphylococcus aureus is often found to be increased on the skin of adolescent or adult patients. Moreover, in head-neck-shoulder dermatitis sensitization to saprophytes of the Malassezia species is more commonly present. In the long version of the atopic dermatitis guideline, several clinical studies of the efficacy of antiseptics and two studies of the efficacy of antifungal agents in atopic dermatitis are mentioned or summarized, the results of which have contributed to the recommendations in this guideline.

\section{Recommendations}

_ If there is no response to topical glucocorticosteroids/calcineurin inhibitors and/or evident superinfection, the use of an additional antimicrobial therapy (topical antiseptic) can be considered in chronic recurrent or chronic eczema.

_ Treatment with systemic antibiotics is recommended in eczema with clear clinical signs of bacterial superinfection. On the basis of current resistance spectra, cephalexin, which is effective exclusively against gram-positive bacteria, or another firstgeneration cephalosporin can be recommended.

_ Longer-term use of topical antibiotics (incl. fusidic acid) is not recommended because of the risk of development of resistance and also, with some topical antibiotics, because of the risk of sensitization.

_ Antifungal therapy can be considered for the clinical picture of head-neck-shoulder dermatitis. This applies especially for patients with atopic dermatitis and marked sensitization to Malassezia species. 


\subsubsection{Antimicrobial clothing}

In recent years, the efficacy of antimicrobial clothing coated with silver nitrate or a quaternary ammonium compound has been studied. In the long version, ten studies with small patient populations are summarized.

\section{Recommendation}

- Wearing antimicrobial underwear (e. g., underwear containing silver nitrate) can be considered in chronic atopic dermatitis.

\subsection{Antihistamines}

A clear therapeutic effect of nonsedating $\mathrm{H} 1$ antihistamines on the skin condition in atopic dermatitis cannot be deduced from available clinical studies. Comedication with $\mathrm{H} 1$ antihistamines can be justified in individual cases of atopic dermatitis because of the reduction of pruritus and sedation. If patients exhibit anxiety states after taking antihistamines, this can be attributable to a paradoxical reaction and the product must be discontinued. However, due to their highly unfavorable risk-benefit profile, the Commission on Drug Safety in Children of the German Society of Pediatrics and Adolescent Medicine advises against the use of sedating over-the-counter antihistamines (including doxylamine, diphenhydramine, dimenhydrinate (diphenhydramine theophyllinate), and promethazine (Position Paper of the Commission on Drug Safety in Children of the German Society of Pediatrics and Adolescent Medicine 2012 and [18]).

\section{Recommendations}

- There is no evidence for the benefit of $\mathrm{H} 1$ antihistamines for the treatment of pruritus in atopic dermatitis. In individual cases of severe acute flare-ups, $\mathrm{H} 1$ antihistamines can be used in combination with other treatment measures.

_ Use of topical $\mathrm{H} 1$ receptor antagonists is not recommended.

- $\mathrm{H} 2$ antihistamines are not recommended for the treatment of atopic dermatitis.

\subsection{Mast cell stabilizers (cromoglycate) and ketotifen}

Oral cromoglycate, nedocromil and ketotifen did not shown any therapeutic effect on atopic dermatitis in clinical studies.

\section{Recommendation}

- Mast cell stabilizers and ketotifen are not recommended for the treatment of atopic dermatitis.

\subsection{Specific immunotherapy}

Specific immunotherapy with allergens (hyposensitization) has a firm position in the therapy of respiratory allergic diseases (allergic rhinitis, mild allergic bronchial asthma) when the clinical relevance of an IgE-mediated sensitization to the allergen is confirmed. From the studies summarized in the long version of the guideline, it can be concluded cautiously that subcutaneous specific immune therapy with house dust mite allergens can probably be effective in a subgroup of highly sensitized adult patients with atopic dermatitis; deterioration of the atopic dermatitis was not observed in clinical studies with specific immunotherapy.

\section{Recommendations}

- Subcutaneous specific immunotherapy in the approved indication (allergic rhinitis, mild allergic bronchial asthma, insect toxin allergy) with coexisting atopic dermatitis can be recommended (see S2 guideline "Specific immune therapy with allergens", [19]).

- Use of the therapy only because of the atopic dermatitis can be considered in severely affected patients when aerogen-triggered eczema is suspected with corresponding evidence of sensitization.

\subsection{Oral glucocorticosteroids}

On the basis of uncontrolled observations (experience-based knowledge), clear efficacy of oral glucocorticosteroids can be assumed.

\section{Recommendations}

- Short-term therapy with oral glucocorticosteroids to interrupt the acute exacerbation can be considered, especially in the treatment of adult patients with severe forms of atopic dermatitis.

- Because of the undesirable drug effects, longerterm treatment of atopic dermatitis with systemic glucocorticosteroids is not recommended. 


\subsection{Ciclosporin}

Ciclosporin is an immunosuppressant drug licensed since 1997 for the treatment of severe atopic dermatitis in adulthood, and the evidence of efficacy is very good (see long version). Please refer also to the S1 guideline on the use of ciclosporin in dermatology; practical aspects are emphasized there in particular [20].

\section{Recommendations}

- The use of ciclosporin A can be recommended for the treatment of chronic severe atopic dermatitis in adulthood.

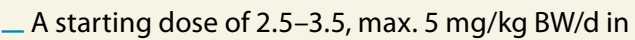
two divided doses is recommended.

_ Induction therapy is recommended in atopic dermatitis, with treatment with an effective dose between $2.5-5 \mathrm{mg} / \mathrm{kg}$ BW/d continued until an improvement of the dermatosis has been largely achieved. It is then recommended to reduce the dose gradually. Following response, a dose reduction by $0.5-1.0 \mathrm{mg} / \mathrm{kg} \mathrm{BW} / \mathrm{d}$ at two-weekly intervals to the individual maintenance dose can be recommended. Before the start of treatment, detailed tests of general physical and in particular nephrological status should be performed.

- If there is a good response, interruption of therapy is recommended after 4-6 months.

- Treatment over a prolonged period can be considered for severe atopic dermatitis (if well tolerated).

- In the treatment of atopic dermatitis with ciclosporin, measurement of the ciclosporin trough blood levels is not recommended.

_ Ciclosporin can also be considered as a possible off-label option in the treatment of children and adolescents who have a refractory and very severe course of atopic dermatitis.

_ Protective vaccinations with live vaccines are not recommended during treatment with ciclosporin because of the possible absence of successful vaccination or because of possible complications. A treatment break of two weeks before and 4-6 weeks after vaccinations must therefore be observed.

- Because of the increased carcinogenesis risk, therapy with ciclosporin A must not be combined with phototherapy.

_ Optimal UV light protection is recommended when ciclosporin is taken.

\subsection{Azathioprine}

Azathioprine has been used in Anglo-American countries for many years in the treatment of severe atopic dermatitis; controlled studies showed efficacy in atopic dermatitis.

\section{Recommendations}

_ Azathioprine (off-label) can be considered in atopic dermatitis if ciclosporin is not effective or is contraindicated.

- Measurement of the enzyme thiopurine methyltransferase (TPMT) before initiation of treatment is recommended so that the dose can be adjusted if necessary to reduce the risk of bone marrow toxicity. A dose of $1-3 \mathrm{mg} / \mathrm{kg} \mathrm{BW} / \mathrm{d}$ is recommended depending on the TPMT activity.

- Independent of this, the azathioprine dose must be reduced to one quarter of the normal dose when xanthine oxidase inhibitors such as allopurinol, oxipurinol or thiopurinol are used at the same time.

_ Phototherapy is not recommended with azathioprine.

_ Optimal UV light protection is recommended when azathioprine is taken.

\subsection{Mycophenolate mofetil}

Mycophenolate mofetil (MMF) is licensed as an immunosuppressant for the treatment of nephritis in systemic lupus erythematosus and in transplant medicine; usually open-label clinical studies also indicate efficacy in severe atopic dermatitis.

\section{Recommendation}

- Mycophenolate mofetil can be considered in atopic dermatitis in adults at up to $2 \mathrm{~g}$ daily, observing the off-label criteria, if ciclosporin is not effective or is contraindicated

\subsection{Methotrexate}

Methotrexate (MTX) was shown to be effective in severe atopic dermatitis in recent controlled studies.

\section{Recommendation}

- Methotrexate (off-label) can be considered in atopic dermatitis if ciclosporin is not effective or is contraindicated. 


\subsection{Biological agents}

\subsubsection{Monoclonal anti-IgE antibodies}

Anti-IgE (omalizumab) is licensed for the treatment of severe allergic bronchial asthma and severe urticaria. The effects of treatment in atopic dermatitis have been rather disappointing to date.

Recommendation

- Treatment of atopic dermatitis with omalizumab is not recommended.

\subsubsection{Other biologicals}

On the basis of positive case reports, there is limited experience for the use of ustekinumab, rituximab, tocilizumab and alefacept in atopic dermatitis. The as yet unlicensed anti-IL4R antibody dupilumab was shown to be effective in clinical studies of atopic dermatitis [21].

\section{Recommendation}

_ Current studies do not allow any assessment of biologicals in atopic dermatitis.

\subsection{Alitretinoin}

Alitretinoin is licensed for the treatment of chronic hand eczema and works particularly well in hyperkeratotic forms. In a published case series, therapy effects on coexisting atopic dermatitis were also shown.

Recommendation

The treatment of hand eczema in the licensed indication can also be considered when concomitant atopic dermatitis is present.

\section{Non-drug therapy methods}

\subsection{Phototherapy}

Phototherapy has achieved firm status in recent decades. Unlike in other countries such as Great Britain, the therapy is not linked to clinics in Germany, Austria and Switzerland, but is also offered by dermatologists in private practice.

\section{Recommendations}

- Phototherapy (UVA-1 therapy, UVB narrowband therapy, UVB broadband therapy, balneo phototherapy) can be recommended as adjuvant therapy in acute disease periods of atopic dermatitis in patients $\geq 18$ years. In patients $>12$ years, phototherapy can be considered.

_ The use of long-wave light ( $>380 \mathrm{~nm}$ ) is not recommended for the treatment of atopic dermatitis in the absence of controlled studies.

\subsection{Immune absorption and 4.3 extracorporeal photopheresis}

Both methods led to improvement of severe atopic dermatitis in smaller published case series (see long version).

\section{Recommendation}

- Treatment with the aforementioned methods can be considered in exceptional cases of very severe atopic dermatitis when ciclosporin and other immunosuppressants are not effective or are contraindicated.

\subsection{Lactobacilli}

In summary, there is no convincing evidence to date from controlled studies that probiotics have a positive effect on the severity and course of atopic dermatitis. Different dosages and strains in the studies, however, make a final assessment difficult.

\section{Recommendation}

- The treatment of atopic dermatitis with lactobacilli cannot be recommended on the basis of current studies.

With regard to the prevention of atopic dermatitis with lactobacilli please refer to the 2014 AWMF guideline by Schäfer et al. [9].

\subsection{Atopic dermatitis education}

Ambulant atopic dermatitis education was examined with regard to efficacy in an interdisciplinary pilot scheme in Germany with the support of the Federal Health Ministry (BMG) and the statutory health insurers (GKV). On the basis of the results of the pilot scheme, the German Federal Association of Health Insurance Funds in 2007 recommended meeting the costs for education programs for atopic dermatitis; the recommendation was updated in 2014. 


\section{Recommendation \\ _ Structured interdisciplinary atopic dermatitis education according to the curriculum of the Arbeitsgemeinschaft Neurodermitisschulung (AGNES) e.V. (Atopic dermatitis education wor- king group) is recommended for legal custodians of children in the age group up to 7 years and for children (8-12 years) and their legal custodians and for patients $\geq 13$ years with chronic or chronic recurrent atopic dermatitis.}

\subsubsection{Self-help organizations}

\section{Recommendation}

_ It is recommended to inform patients with atopic dermatitis of existing self-help groups and encourage them to take part.

\subsection{Elimination diets}

Roughly half of infants and toddlers with persistent eczema also show sensitization to foodstuffs at the same time. Sensitization to foodstuffs is often found in older patients also. However, a current clinical allergy to food components exists in only a minority of patients with atopic dermatitis. Dietary intervention in patients with atopic dermatitis, especially affected infants and toddlers, is justified only when a current food allergy has been demonstrated. There is no general „atopic dermatitis diet“.

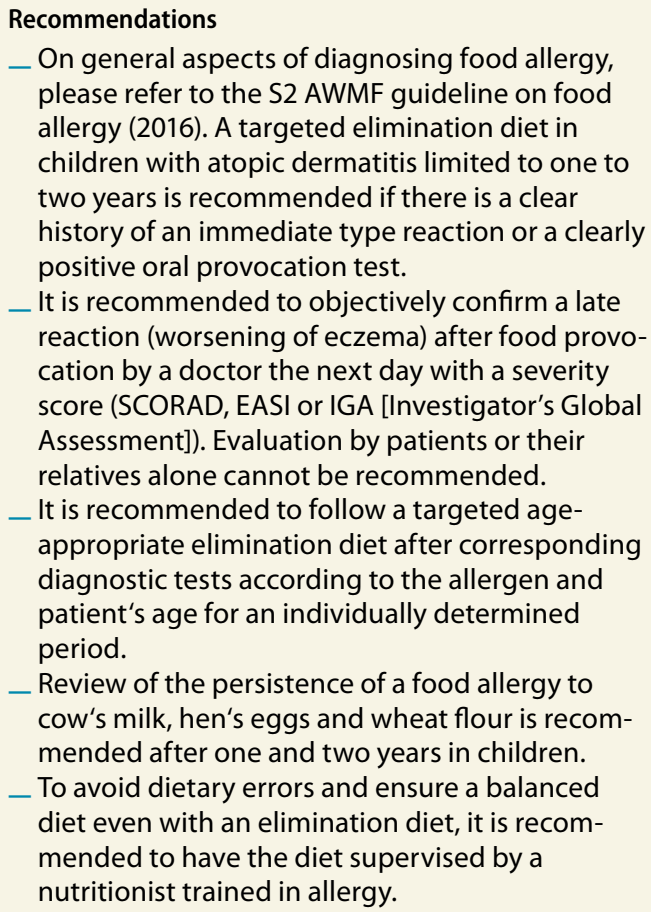

\subsection{Essential fatty acids}

Against the background of detectably reduced delta6-desaturase activity in atopic dermatitis, a series of studies of supplementation with essential n- 6 fatty acids was conducted, which did not show any effects on atopic dermatitis. On the basis of new findings, the role of n-3 fatty acids has been discussed recently but controlled studies are lacking, with the exception of one smaller study in which these were given intravenously.

\section{Recommendations}

_ Oral administration or topical application of $n-6$ fatty acids in atopic dermatitis cannot be recommended.

_ In particular, dietary substitution with borage oil or evening primrose oil (gamma-linolenic acid) and the topical use of gamma-linolenic acid for the treatment of atopic dermatitis with the aim of clinical improvement cannot be recommended in atopic dermatitis.

- The intravenous use of n-3 fatty acids cannot be recommended.

\subsection{House dust mite reduction}

Many patients with atopic dermatitis are sensitized particularly obviously to house dust mites. Measures to reduce house dust mites had some positive effects on the skin condition of these patients in studies (see long version).

\section{Recommendation}

_ Encasing can be considered in sensitized patients with atopic dermatitis.

\subsection{Psychological treatment}

Psychological and emotional factors are regarded as relevant influences in atopic dermatitis even if it is not certain to what extent such factors can in turn be influenced by the eczema. In controlled studies, behavior therapies have shown efficacy in atopic dermatitis.

\footnotetext{
Recommendations

_ Psychological therapy can be considered for individual patients with atopic dermatitis. Behavior therapy interventions can be recommended.

- The use of psychological therapy can be recommended only when there is a clear indication (psychological factors as individual trigger factors of atopic dermatitis or if the atopic dermatitis has secondary psychosocial consequences for the patient/family).
} 


\section{Updating}

This updated version of the guideline is valid until $05 / 2018$

\section{Financing}

Production of this updated S2k guideline „Atopic dermatitis“ was supported financially by the German Dermatology Society (DDG). Independent of this, all decisions regarding the content of this guideline are based on a consensus of the mandate holders.

\section{Participating specialist societies}

- Werfel Thomas, Deutsche Dermatologische Gesellschaft

_ Aberer Werner, Österreichische Gesellschaft für Dermatologie und Venerologie

- Ahrens Frank, Gesellschaft für Pädiatrische Allergologie und Umweltmedizin e.V.

- Augustin Matthias, Arbeitsgemeinschaft Gesundheitsökonomie und Evidenzbasierte Medizin der Deutschen Dermatologischen Gesellschaft

- Biedermann Tilo, Arbeitsgemeinschaft Dermatologische Forschung

- Diepgen Thomas, Arbeitsgemeinschaft Berufsund Umweltdermatologie der Deutschen Dermatologischen Gesellschaft

_ Fölster-Holst Regina, Arbeitsgemeinschaft Pädiatrische Dermatologie der Deutschen Dermatologischen Gesellschaft

- Gieler Uwe, Deutsche Gesellschaft PM, Arbeitskreis Psychosomatische Dermatologie, Sektion der Deutschen Dermatologischen Gesellschaft

- Heratizadeh Annice, Wissenschaftliche Dokumentation und Redaktion (Methodik, nicht stimmberechtigt)

_ Kahle Julia, Deutscher Allergie- und Asthmabund e.V.

- Kapp Alexander, Deutsche Gesellschaft für Allergologie und Klinische Immunologie

- Nast Alexander, Arbeitsgemeinschaft der Wissenschaftlichen Medizinischen Fachgesellschaften e.V. (Moderation)

- Nemat Katja, Berufsverband der Kinder- und Jugendärzte e.V.

_ Ott Hagen, Deutsche Gesellschaft für Kinderund Jugendmedizin e. V.

_ Przybilla Bernhard, Arbeitsgemeinschaft Allergologie der Deutschen Dermatologischen Gesellschaft

- Roecken Martin, Deutsche Dermatologische Gesellschaft

- Schlaeger Martin, Berufsverband Deutscher Dermatologen e.V.

- Schmid-Grendelmeier Peter, Schweizerische Gesellschaft für Dermatologie und Venerologie

_ Schmitt Jochen, Deutsches Netzwerk Versorgungsforschung e.V.

_ Schwennesen Thomas, Deutscher Neurodermitis Bund e.V.

- Staab Doris, Arbeitsgemeinschaft Neurodermitisschulung e.V.

- Worm Margitta, Deutsche Kontaktallergiegruppe e.V.

\section{Dr. Annice Heratizadeh}

Abteilung Immundermatologie und experimentelle Allergologie

Klinik für Dermatologie, Allergologie und Venerologie Medizinische Hochschule Hannover

Carl-Neuberg-Straße 1, 30625 Hannover, Deutschland

E-Mail: Heratizadeh.Annice@mh-hannover.de

\section{Conflict of interest}

As regards potential conflicts of interests for the authors, please refer to the long version of this guideline (www. awmf.org).

\section{Cite this as}

Werfel T, Heratizadeh A, Aberer W, Ahrens F, Augustin M, Biedermann T, Diepgen T, Fölster-Holst R, Gieler U, Kahle J, Kapp A, Nast A, Nemat K, Ott H, Przybilla B, Roecken M, Schlaeger M, Schmid-Grendelmeier P, Schmitt J, Schwennesen T, Staab D, Worm M. S2k guideline on diagnosis and treatment of atopic dermatitis - short version. Allergo J Int 2016;25:82-95

\section{DOI: $10.1007 / \mathrm{s} 40629-016-0104-6$}

\section{References}

1. Werfel T, Aberer W, Augustin M et al. S2e Leitlinie Neurodermitis. AWMF-Leitlinien-Register Nr. 013/027, 2008

2. Werfel T, Aberer $W$, Augustin $M$ et al. [Atopic dermatitis: S2 guidelines]. J Dtsch Dermatol Ges 2009;7 (Suppl 1):S146

3. Nast A, Sporbeck B, Jacobs A et al. Study of perceptions of the extent to which guideline recommendations are binding: a survey of commonly used terminology. Dtsch Arztebl Int 2013;110:663-8

4. Ring J, Alomar A, Bieber T et al. Guidelines for treatment of atopic eczema (atopic dermatitis). Part I. J Eur Acad Dermatol Venereol 2012;26:1045-60

5. Ring J, Alomar A, Bieber T et al. Guidelines for treatment of atopic eczema (atopic dermatitis). Part II. J Eur Acad Dermatol Venereol 2012;26:1176-93

6. Werfel T, Schwerk N, Hansen G et al. The diagnosis and graded therapy of atopic dermatitis. Dtsch Arztebl Int 2014:111:509-20

7. Schmitt J, Schmitt NM, Kirch W et al. [Significance of atopic dermatitis in outpatient medical care. Analysis of health care data from Saxony]. Hautarzt 2009;60:320-7

8. Schmitt J, Schmitt NM, Kirch W et al. Outpatient care and medical treatment of children and adults with atopic eczema. J Dtsch Dermatol Ges 2009;7:345-51

9. Schäfer T, Bauer CP, Beyer K et al. S3-Leitlinie Allergieprävention - Update 2014. AWMF-Leitlinien-Register Nr. 061/016, 2014

10. Robert Koch Institut, ed. Empfehlungen der Ständigen Impfkommission. http://www.rki.de/DE/Content/Kommissionen/STIKO/Empfehlungen/Impfempfehlungen_ node.html

11. Jenneck C, Foelster-Holst R, Hagemann T et al. [Associated diseases and differential diagnostic considerations in childhood atopic eczema]. Hautarzt 2007;58:163-74; quiz 75-6

12. Schmitt J, Spuls P, Boers M et al. Towards global consensus on outcome measures for atopic eczema research: results of the HOME II meeting. Allergy 2012;67:1111-7 
13. Schmitt J, Langan S, Deckert S et al. Assessment of clinical signs of atopic dermatitis: a systematic review and recommendation. J Allergy Clin Immunol 2013;132:133747

14. Werfel T, Claes C, Kulp W et al. Therapy of atopic eczema. GMS Health Technol Assess 2006;2:Doc19

15. Beikert FC, Langenbruch AK, Radtke MA et al. Willingness to pay and quality of life in patients with atopic dermatitis. Arch Dermatol Res 2014;306:279-86

16. Dickel H, Bruckner TM, Schmidt A et al. Impact of atopic skin diathesis on occupational skin disease incidence in a working population. J Invest Dermatol 2003;121:3740
17. John SM, Skudik C, Römer W, Brandenburg ST, Diepgen TL. Hautarztverfahren. AWMF-Registernummer 013-082, 2010

18. Seyberth HW. Medizinreport Pädiatrie: Rezeptfreie Antihistaminika bergen Risiken für Kleinkinder. Dtsch Arztebl 2012;109:A-1822/B-476/C-452

19. Pfaar O, Bachert C, Bufe A, Buhl R, Ebner C. Leitlinie zur (allergen-)spezifischen Immuntherapie bei IgE-vermittelten allergischen Erkrankungen. Allergo J Int 2014;23:28-65

20. Mrowietz U, Klein CE, Reich K et al. Cyclosporine therapy in dermatology. J Dtsch Dermatol Ges 2009;7:474-9

21. Beck LA, Thaci D, Hamilton JD et al. Dupilumab treatment in adults with moderate-to-severe atopic dermatitis. $\mathrm{N}$ Engl J Med 2014;371:130-9 